\title{
Pain assessment strategies in patients with musculoskeletal conditions
}

\author{
F. Salaffi ${ }^{1}$, A. Ciapetti ${ }^{1}$, M. Carotti ${ }^{2}$ \\ ${ }^{1}$ Rheumatology Department, Politechnic University of the Marche, Ancona, Italy; \\ ${ }^{2}$ Radiology Department, Politechnic University of the Marche, Ancona, Italy
}

\begin{abstract}
SUMMARY
Valid and reliable assessment of pain is fundamental for both clinical trials and effective pain management. The nature of pain makes objective measurement impossible. Chronic musculoskeletal pain assessment and its impact on physical, emotional and social functions require multidimensional qualitative tools and healthrelated quality of life instruments. The recommendations concerning outcome measurements for pain trials are useful for making routine assessments that should include an evaluation of pain, fatigue, disturbed sleep, physical functioning, emotional functioning, patient global ratings of satisfaction, and quality of life. Despite the growing availability of instruments and theoretical publications related to measuring the various aspects of chronic pain, there is still little agreement and no unified approach has been devised. There is, therefore, still a considerable need for the development of a core set of measurement tools and response criteria, as well as for the development and refinement of the related instruments, standardized assessor training, the cross-cultural adaptation of health status questionnaires, electronic data capture, and the introduction of valid, reliable and responsive standardized quantitative measurement procedures into routine clinical care. This article reviews a selection of the instruments used to assess chronic musculoskeletal pain, including validated newly developed and well-established screening instruments, and discusses their advantages and limitations.
\end{abstract}

Key words: Chronic musculoskeletal pain, measurement tools, pain scales, health-related quality of life, clinimetric properties.

Reumatismo, 2012; 64 (4): 216-229

\section{INTRODUCTION}

M usculoskeletal conditions affect hundreds of millions of people around the world (1-3) and are the most common cause of severe long-term pain and physical disability. The reported disease prevalence of musculoskeletal complaints ranges widely from $9.8 \%$ to $33.2 \%$ (4-8), and it has been estimated that $15-45 \%$ of general practitioner consultations are for musculoskeletal problems $(9,10)$. Almost onethird of people over the age of 75 years has a significant musculoskeletal problem, and the prevalence of locomotor disability rises from $3.1 \%$ in those under the age of 60 years to almost $50 \%$ in those over the age of 75 years $(11,12)$. This demonstrates that an important part of health care resources is directed to musculoskeletal disorders $(13,14)$, and that this economic burden should not be underestimated (15). In Italy, the overall prevalence of musculoskeletal conditions in the general adult population was $26.7 \%$ (95\% CI 25.4-28.5), being significantly higher among women than men (16). On the other hand, other studies have estimated the prevalence of self-reported symptoms or musculoskeletal conditions as ranging from $12.4 \%$ to $44.3 \%$ in various adult populations (16-19). A careful assessment of long-lasting pain is, therefore, a more demanding task than assessing acute pain for both clinical practice and clinical trials.

This review considers the methodological issues concerning the clinimetric properties of a number of instruments currently used to assess patients with chronic musculoskeletal pain that are dimension and symptom specific, and include measurements of widespread pain, fatigue, sleep disturbance, mood, and overall well-being. Although not exhaustive, it has been based on an extensive search of the related literature and the experience of the authors, and 
is intended to provide recommendations for daily clinical practice.

\section{Strategies for identifying and assessing musculoskeletal pain in adults}

A comprehensive assessment of any chronic complex pain condition should be based on a biopsychosocial model that emphasizes the important interaction of biological, psychological, and social/cultural contributors to the experience of pain and requires documentation of:

1. pain history and intensity;

2. physical functioning and quality of life;

3. emotional functioning;

4. patient ratings of improvement or worsening of the pain (20-23).

These recommendations are consistent with the core outcome domains specified in the Methods, Measurement, and Pain Assessment in Clinical Trials (IMMPACT) consensus (23), the recommendations of the Consolidated Standards of Reporting Trials (CONSORT) guidelines (24), the Outcome Measurement in Rheumatoid Arthritis Clinical Trials (OMERACT) (25), and the World Health Organization/Inter- national League of Associations for Rheumatology (WHO/ILARS) (26) (Tab. I).

Given the multifaceted nature of chronic musculoskeletal pain and the new therapies currently being tested, there is a need to further refine these domains in order to develop a reliable and valid composite patient-reported outcome (PRO) response measurement tool that more accurately assesses treatment effects. The validity, reliability and responsiveness of PRO data in evaluating and monitoring patients with rheumatic conditions have been clearly documented (27).

\section{Chronic pain measurement tools}

Pain assessment is an interactive and collaborative process involving the patient and his/her family, nurse, physician, and other health professionals who all provide the basis for selecting correct patient management. Ongoing comprehensive assessment is the cornerstone of effective chronic pain management, including an interview, physical assessment, medication review, medical and surgical review, psychosocial review, review of physical environment and

Table I - Recommendations for assessing musculoskeletal pain in adults.

\begin{tabular}{|c|}
\hline Evaluation of patient's history, interview information and results of physical examinations. \\
\hline $\begin{array}{l}\text { Make adjustments to accommodate the patient' sensory deficits (e.g., provide written and oral instructions, use } \\
\text { enlarged type and bold figures). }\end{array}$ \\
\hline Determine ability to complete the pain interview and to use available pain scales. \\
\hline Provide clear, simple instructions on the use of the pain scales each time administered to assure understanding. \\
\hline $\begin{array}{l}\text { Identify an assessment tool that the patient can easily use. If the use of a Numeric Rating Scale (NRS) is } \\
\text { questionable or the NRS is not the institution standard, the verbal descriptor scale (VDS) or Pain Thermometer } \\
\text { have been shown to be the most preferred and easiest to understand tools and are recommended for those } \\
\text { patients who are literate. The Faces Pain Scale is another alternative that is useful for some older adults. }\end{array}$ \\
\hline $\begin{array}{l}\text { Use the same tool consistently with each assessment and standardize the conditions (e.g., medication use, } \\
\text { function/activities being performed) and time of assessment. It is imperative that reassessments of pain and } \\
\text { effectiveness of treatments be conducted using the same tool as in the original assessment. Pain tools are not } \\
\text { interchangeable and do not represent comparable findings. }\end{array}$ \\
\hline $\begin{array}{l}\text { Documentation concerning the patient's report of pain must be kept in an accessible location. For assessment } \\
\text { data to be useful, they must be communicated across providers and care settings. Documentation procedures } \\
\text { that facilitate monitoring and communication are recommended. }\end{array}$ \\
\hline $\begin{array}{l}\text { Where brief assessment tools are needed, the VDS and the NRS are, generally, recommended for the assessment } \\
\text { of pain intensity among patients who are cognitively intact and can self-report. }\end{array}$ \\
\hline $\begin{array}{l}\text { Where a more detailed self-report assessment of functional impact is possible, the Brief Pain Inventory or the } \\
\text { Chronic Pain Grade Questionnaire should be considered. For detailed assessment of pain qualities, the McGill } \\
\text { Pain Questionnaire should be used for cognitively intact, patients who are literate. }\end{array}$ \\
\hline $\begin{array}{l}\text { A comprehensive pain assessment should also include evaluations of impact of pain on related aspects of the } \\
\text { patient's functioning and quality of life (e.g. associated symptoms, sleep disturbance, fatigue, physical activity } \\
\text { changes, concentration, and relationships with others). }\end{array}$ \\
\hline
\end{tabular}

VDS, Verbal Descriptive Scales; NRS, Numeric Rating Scales. 
the appropriate diagnostics. Assessment must determine the pain duration, frequency, intensity or severity, location, onset/pattern, quality or character effectiveness of treatments and impact on quality of life for patients and their families. Self-reporting is the primary source and this facilitates regular reassessment and follow up (28). Various pain measurement scales have been developed but none are suitable for all patients. Furthermore, using these tools interchangeably is still not justified (29).

\section{Single-dimension assessment pain scales}

In clinical settings, the instruments for measuring pain must be simple, quick to administer, and easily understood by the patient. The most used scales are visual, verbal and numerical or some combination of all three.

- Visual. Visual scales have pictures of human anatomy to help you explain where your pain is located. A popular visual scale (Faces Pain Scale) is particularly useful for children, who sometimes do not have the vocabulary to explain how they feel.

- Verbal. Verbal scales contain commonly used words such as low, mild or excruciating to help you describe the intensity or severity of your discomfort. Verbal scales are useful because the terminology is relative, and you must focus on the most characteristic quality of your pain.

- Numerical. Numerical scales help you to quantify your pain using numbers, sometimes in combination with words.

Unidimensional scales provide rapid measurements and can be administered repeatedly with minimal administrative effort $(28,29)$ (Tab. II).

Among several subjective methods for pain intensity measurement, visual analog scales (VAS), numerical rating scales (NRS), and verbal rating scales (VRS) proved to be reliable and valid. The three scales are significantly different from each other for the number of response categories, patient and clinician preference, likelihood of missing data and administration requirements (28-31). Although variations exist, the VAS typically consists of scores from $0-10$ (or 0-100), with the far left being described as no pain and the far right as worst possible pain (Fig. 1).

The VAS provides a high degree of resolution and is probably the most widely used single-item measurement tool in clinical pain research (32). However, disadvantages include being difficult to understand, leading to higher failure rates than than those reported for verbal rating scales (VRS) or numerical rating scales (NRS) (32-34), especially in subjects with physical or cognitive impairment and in the elderly $(35,36)$. Evidence shows that the visuospatial abilities required for the use of VAS are more affected by age than the lexical abilities required for use of a VRS or NRS (35-37). VAS are also less reliable

Table II - Single-dimensional assessment tools.

\begin{tabular}{|l|l|l|l|}
\hline Scale & Administration & Indications & Characteristics \\
\hline VAS & Visual & $\begin{array}{l}\text { Chronic pain, rheumatic disease in } \\
\text { children }>7 \text { years }\end{array}$ & $\begin{array}{l}\text { Poor reproducibility postoperatively or } \\
\text { in patients with dementia or cognitive } \\
\text { dysfunction }\end{array}$ \\
\hline NRS & Verbal or visual & $\begin{array}{l}\text { Chronic pain, rheumatic disease, trauma, } \\
\text { cancer, illiterate }\end{array}$ & $\begin{array}{l}\text { Detects treatment effects. Decreased } \\
\text { reliability at extreme of ages, pre-verbal, } \\
\text { visual, auditory or cognitive dysfunction }\end{array}$ \\
\hline VNS & Visual & $\begin{array}{l}\text { Chronic pain, rheumatic disease, trauma, } \\
\text { cancer, illiterate }\end{array}$ & Easier for older adults \\
\hline GRS & Visual & $\begin{array}{l}\text { Chronic pain, rheumatic disease in } \\
\text { children }>7 \text { years }\end{array}$ & Less reliable in illiterate patients \\
\hline VDS & Verbal or visual & Adults & Easier for older adults \\
\hline FPS & Visual & Adults, children & $\begin{array}{l}\text { Easier than NRS or VAS, no influence on } \\
\text { culture, gender or ethnicity }\end{array}$ \\
\hline
\end{tabular}

VAS, Visual Analogue Scale; NRS, Numeric Rating Scales; VNS, Visual Numeric Scale; GRS, Graphic Rating Scale; VDS, Verbal Descriptive Scales; FPS, Faces Pain Scales. 
in illiterate patients. Understanding may be improved by the addition of markers to form a graphic rating scale (GRS) (Fig. 1). These scales include a horizontal line that is anchored at both ends (no pain and worst possible pain) and graded 0-10 (or 0-100). Studies in other fields of medicine indicate that the anchors improve reliability and sensitivity, and do not necessarily lead to excessive marker bias (i.e. the tendency to be drawn towards the markers when completing the scale). The NRS scale (Fig. 1), numbered $0-10$, is another valid alternative. This scale, usually shown to patients as a horizontal line, is more practical, easier to understand for most people, and does not need clear vision, dexterity or pen and paper $(28,29,38,39)$. The NRS may be used either verbally or visually. However, research indicates that the vertical NRS is more sensitive and easier for patients to use. This is especially true for patients who are under stress with a narrowed visual field. For this reason, the vertical NRS may be used for some patient populations or offered as an alternative to patients who have difficulty with the horizontal scale. It is also possible to determine the intensity of pain accurately using a normal or computerized telephone interview; in the latter, patients register the data directly in a database via their telephone keyboard. Pincus et al. (40) found that a circle with 21 numbers and an arithmetic scale offers an optimal alternative to a $10 \mathrm{~cm}$ horizontal line, over which it has at least three advantages:

1. it can be scored without a ruler, thus saving about half the time;

2. it eliminates the need to reproduce an exact $10 \mathrm{~cm}$ line when printing or photocopying questionnaires, thus avoiding the problem of minor distortions;

3. patients seem to understand how to respond better (some patients write words or even sentences on a line).

Sometimes descriptive terms such as none, mild, moderate, severe, very severe are used for subjects who have difficulty in translating their pain experience into a number to form a descriptive verbal scale (DVS) (Fig. 1). It includes adjectives that reflect the extremes (e.g. no pain to worst possible pain) and sufficient adjectives to capture gradations in between. However, this type of measurement tool has a number of statistical drawbacks and is usually used only as a coarse screening instrument (29, $34,37)$. The VAS and NRS agree well and are equally sensitive in assessing pain, and they are both superior to a 6-point DVS, but clinical trials have shown that NRS are more reliable, especially with less educated patients (35-38). The simplicity and ease of obtaining pain ratings is an overriding criterion for pain assessment in clinical settings, as shown by the prevalence of the use of a simple $0-10 \mathrm{~cm}$ NRS $(35,39,41)$.

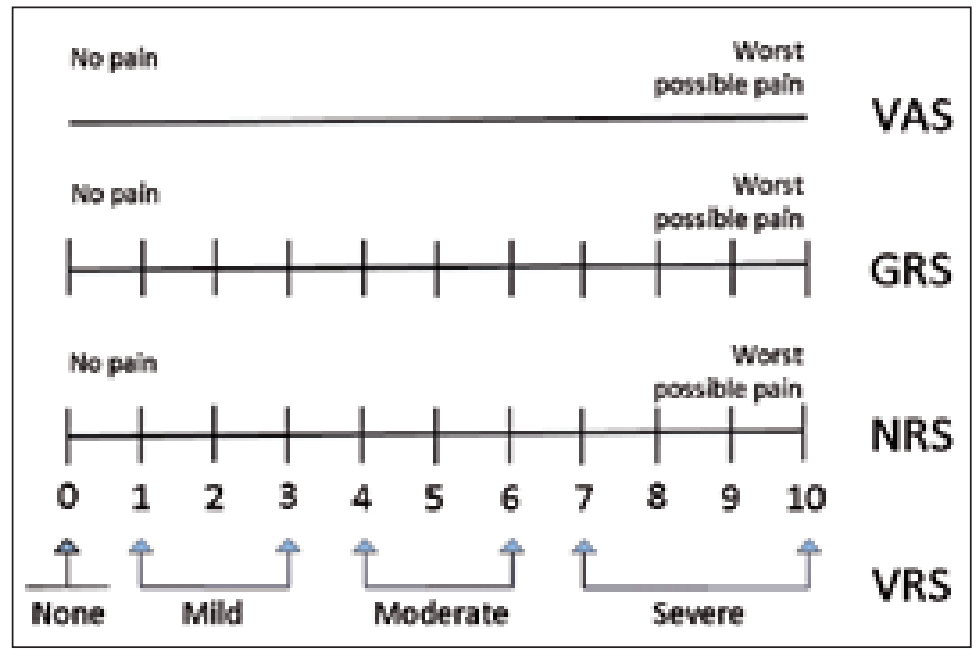

Figure 1 - The most common used one-dimensional pain intensity scales. The visual analog scale (VAS) consists of a line, usually 100 $\mathrm{mm}$ long, whose ends are labeled as the extremes (no pain and worst pain imaginable); the rest of the line is blank. The patient is asked to put a mark on the line indicating their pain intensity (at the present time, over the past week, or over the past 2 weeks, etc.). The distance between that mark and the origin is measured to obtain the patient's score. The addition of markers to the traditional pain VAS form a graphic rating scale (GRS). This scale includes a horizontal line with vertical bars of increasing height and anchors at both ends (no pain and worst possible pain). The line is graded from 0 to 10 (or from 0 to 100). The numerical rating scale (NRS) involves asking patients to rate their pain intensity by selecting a number on a scale from 0-10 (11-point scale), 0-20 (21-point scale), or 0-100 by filling in a questionnaire or stating verbally a numerical level (please indicate on the line below the number between 0 and 10 that best describes your pain. A 0 would mean no pain and a 10 would mean worst pain immaginable). Sometimes descriptive terms, such as none, mild, moderate and severe, are provided along the scale (this forms a verbal rating scale, VRS) for guidance, as shown, and the scale is then referred to as a GRS. 
Global ratings of improvement and satisfaction in a clinical trial provide an opportunity for participants to aggregate all of the components of their experience (pain relief, improvement in physical and emotional functioning, side effects, convenience) into one overall measurement of their perception of the advantages and disadvantages of the treatment they received. Such measurements reflect the disparate values and preferences of individual patients and in so doing provide an important measurement of pain treatment outcome. Many different approaches have been used to assess participants' overall evaluation of their treatment in clinical trials. For example, the PGIC (Patient Global Impression of Change) scale provides a single, general estimate of improvement. The typical PGIC asks patients to rate their current status as:

1) very much improved;

2) much improved;

3) minimally improved;

4) no change;

5) minimally worse;

6) much worse;

7) very much worse.

This measurement tool has the advantage of being applicable in a wide variety of conditions and treatments. They have also been used to determine the minimally important changes in quality of life measurements (42). Other scales put numbers, descriptive words and colors along a VAS, such as the Visual Numeric Scale (VNS), the Anchored Logarithmic Scale (ALS), the Analogue Chromatic Continuous Scale (ACCS), and pain thermometers or pain rulers (Fig. 2) (28, 43, 44). The VNS was developed to take advantage of the features of numerical scales while providing multiple visual cues, including the height and shading of the bars associated with each number and can, therefore, be considered a combined visual and numerical scale (39). A modified version of a continuous pain VAS is the Anchored Logarithmic Scale proposed by Gracely which is intended to account for the fact that many sensory responses are inherently logarithmic rather than linear (45). This scale uses descriptive anchors spaced along its length, with the spacing of the descriptor representing logarithmic changes in pain intensity. The Pain Thermometer aligns a thermometer alongside the words representing different levels of pain severity (43) (Fig. 2).

The Revised Faces Pain Scale (FPS-R) is a very popular visual scale. Designed for children aged 3 years and over, the FPS-R is also helpful for elderly patients who may be cognitively impaired $(35,46,47)$. If offers a visual description for those who do not have the verbal skills to explain how their symptoms make them feel.

All of these instruments facilitate the understanding and communication of pain severity, particularly among patients with diminished cognitive capacity or who have difficulty with abstract thinking $(43,44)$. It has been shown that older patients prefer thermometer scales considering them to be the easiest to understand, and these are recommended by national and international guideline panels $(43,48,49)$. Patients are

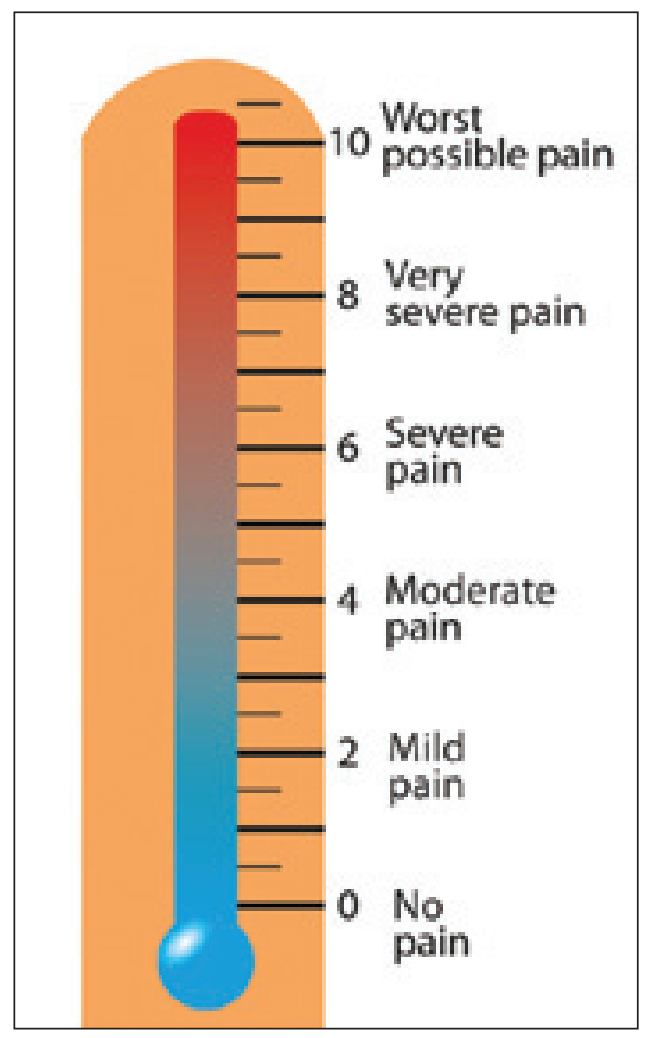

Figure 2 - Example of Thermometer Pain scale. 
shown the scale and asked to think that pain increases as you move to the top of the scale in the same way as temperature rises in a thermometer. These visual scales are excellent for patients with moderate or severe cognitive deficits, or who have difficulty communicating verbally.

\section{Pain location}

Topography of pain can be evaluated by means of the pain drawing, a diagram depicting the front and back of a human body on which the location (and sometimes other qualities) of the pain is marked. In some patients, the drawing might be influenced by psychosomatic disorders and be used to alert the physician accordingly, although there is a lack of high quality evidence to support the use of the pain drawing as a psychological assessment tool. Pain drawings used solely as pain locators generally show reliable results.

\section{Pain diagrams or drawings}

As widespread pain is one of the two fibromyalgia (FM) classification criteria proposed by the American College of Rheumatology (ACR) (49), and widespread pain and/or the extent of pain has been the subject of many investigations, various simple pain diagrams or drawings have been validated (50-52). Two of these are the Regional Pain Scale (RPS) (50) and the Self-Assessment Pain Scale (SAPS) (51).
The RPS is a valid means of measuring the extent of pain that can be used to identify patients with FM, including those with concomitant rheumatoid arthritis (RA) and osteoarthritis (OA). The SAPS considers 16 non-articular sites by asking patients to indicate below the amount of pain and/or tenderness you have experienced in the last 7 days in each of the body areas, and has a series of site descriptions followed by four boxes labelled $0=$ none, $1=$ mild, $2=\bmod$ erate, and $3=$ severe; the possible scores, therefore, range from 0 to 48 but in order to integrate them into one scale they have been transformed into a 0-10 scale (Fig. 3).

\section{Multidimensional pain scales}

In many situations, a simple, one-item instrument is not sufficient to truly capture pain or quality of life $(35,52)$. There are many comprehensive measurements of pain. These instruments typically measure several dimensions of pain $(20,23,25,26)$. By assessing the pain experience in a more complex way, these scales may circumvent the commonly observed lack of association between pain intensity and disability. The most popular multidimensional pain scales are the McGill Pain Questionnaire (MPQ) (53) and the Short-Form (SF) MPQ (54), the Brief Pain Inventory (BPI) (55) and the Chronic Pain Grade (CPG) questionnaire $(56,57)$. These questionnaires typically measure different combinations of vari-

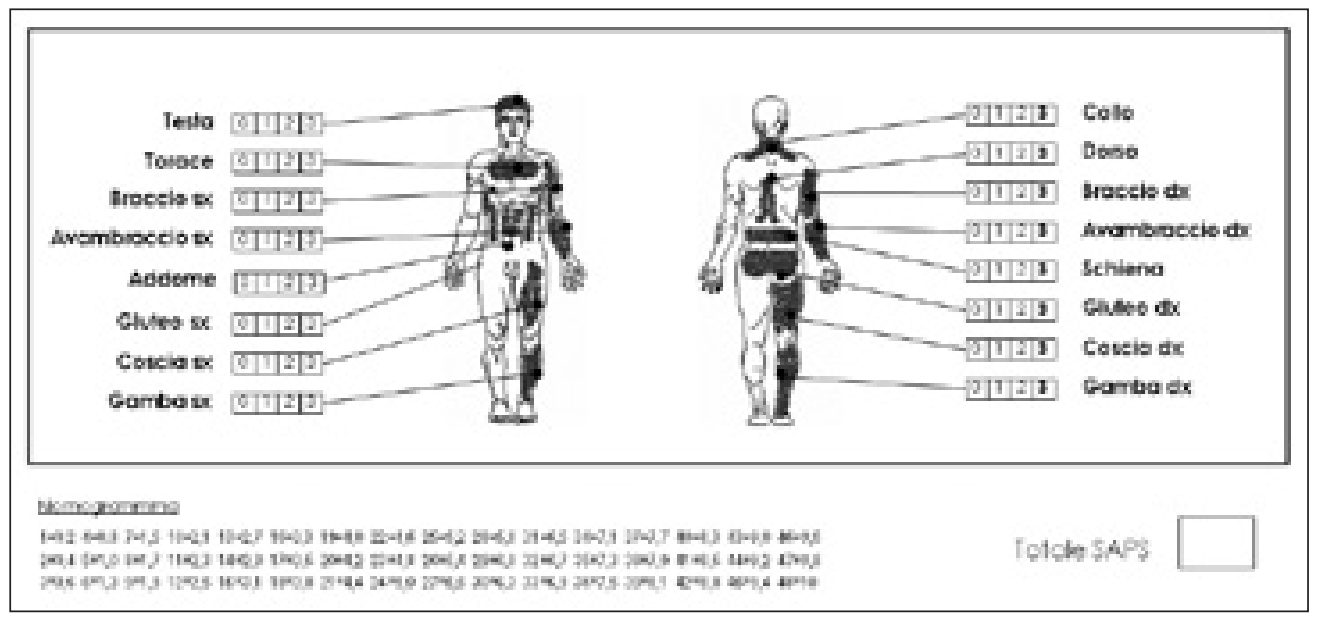

Figure 3 - The Self-Assessment Pain Scale (SAPS) (available online at http://arthritis research. com/content/11/4/R125) (51). 
ous dimensions of pain: pain intensity and quality, affect, its interference with functioning, and its effects on the general quality of life. However, they are often lengthy documents and this may limit patient acceptance, especially when administered during the pain event.

The McGill Pain Questionnaire and Shortform McGill Pain Questionnaire

The complete MPQ is one of most widely tested instruments for measuring and assessing pain, and can provide detailed information on the characteristics of chronic pain $(54,58)$. It is a complex questionnaire (it includes 78 pain adjectives divided into four major categories: sensory, affective, evaluative, and miscellaneous sensory) and takes 15-20 minutes to complete. It also includes questions concerning changes in pain over time, and the classification of pain intensity as mild, discomforting, distressing, horrible and excruciating (54). It is, therefore, not easily administered in a non-research clinical setting, and simpler measures, such as VAS, have become more widely accepted for use in clinical research, clinical trials and clinical care. The Short Form (SF)-MPQ is a 15 -item selfreport scale derived from the original MPQ (55) that contains three components. The pain rating index consists of 15 representative words rated on a 4-point Likert-type scale ranging from 0 (none) to 3 (severe): 11 sensory (e.g. tender) and four affective (e.g. sickening). There are also two items measuring pain intensity. Overall pain is assessed using an NRS consisting of a 10 $\mathrm{cm}$ visual line that approximates ratings between 0 (no pain) and 10 (unbearable pain).

The Brief Pain Inventory (BPI) was developed to provide information concerning the intensity of pain (the sensory dimension) and the degree of pain that interferes with seven aspects of life: general activities, walking, normal work, relations with other people, mood, sleep, and the enjoyment of life (the reactive dimension). It also documents pain location on a body chart and the characteristics of the pain. It can be self-administered, or administered during a clinical interview or even over the telephone. As pain may vary during the course of a day, the BPI asks patients to rate their pain at the time of responding to the questionnaire (pain now), and also at its worst, least, and average over the previous week. Ratings may also be made for the previous 24 hours.

The Chronic Pain Grade (CPG) questionnaire $(56,57)$ consists of seven items. Current pain intensity, worst pain intensity and average pain intensity in the previous six months are assessed by three items (1-3) using an 11-point rating scale $(0=$ no pain, $10=$ pain as bad as it could be); one item assesses the number of days during that period on which the respondent has been kept from his/her usual activities (work, school, housework), and the remaining three items (5-7) assess disability in the previous six months. The extent of interference with daily activities, the ability to take part in recreational, social and family activities, and the ability to work (including housework) are assessed using an 11-point rating scale ( $0=$ no interference, $10=$ unable to carry on any activities). The questionnaire classifies chronic pain into four hierarchical grades: grade I (low disability-low intensity), grade II (low disability-high intensity), grade III (high disability-moderately limiting) and grade IV (high disability-severely limiting) (56, 57). The CPG also assesses the number of days in the previous six months on which the subject was unable to carry out usual activities (work, school, housework) due to pain (days in pain). The questionnaire is easy to complete, and its brevity makes it attractive if correctly used.

\section{Fatigue assessment}

Fatigue is defined as an experience of feeling weak, tired and lacking energy that often comes and goes in normal circumstances. Patients with chronic pain say that fatigue is a common and debilitating symptom of their illness. The presence and severity of fatigue have been ascribed to a variety of causes, including disease activity, a lack of aerobic fitness, psychological depression, sleep disturbances, and co- 
morbid medical conditions. Although the etiology of fatigue is not always clear in individual patients, it is associated with a reduced quality of life and is often difficult to manage. Research into rheumatic conditions has identified a set of valid and reliable fatigue measurement scales based on rigorous evaluation standards, and the recommendations of the IMMPACT concerning outcome measurements for pain trials endorsed the proposal that fatigue should be measured in future studies of patients with chronic widespread pain.

\section{Unidimensional fatigue measurements}

Although fatigue can be assessed unidimensionally (e.g. by means of an intensity measurement alone), as a dichotomous variable (the presence or absence of a defined criterion), or by using 5 or 6-point DVS or NRS scales, the simplicity of these approaches needs to be balanced against the missed opportunity of capturing information concerning other dimensions, including qualitative differences that could potentially distinguish clinically meaningful fatigue subtypes. These simple scales presumably provide a global measure of fatigue severity (Tab. III). Another measurement that has been validated in a number of rheumatic conditions is the vitality scale of the Medical Outcomes Study (MOS) 36-Item Short-Form Health Survey (MOS-SF36 -VT) (59-61) which explores fatigue and the related concept of energy level. The item responses are rated using a 6-point Likert scale (from all of the time to none of the time), and the score can vary from 0 (the worst) to 100 (the best).
Multidimensional fatigue measurements Multidimensional fatigue measurements capture more information about the characteristics or impact of fatigue, such as the global quality of life and symptom distress. A variety of measurement tools have proved to be useful in measuring fatigue in FM and other chronic conditions, including the Multidimensional Assessment of Fatigue (MAF) (62) and the Multidimensional Fatigue Index (MFI) (63) which measures various types of fatigue including physical and emotional fatigue. Another measurement tool validated in a number of disease states is the Functional Assessment of Chronic Illness Therapy (FACIT-Fatigue) system (64) which may be customized to certain disease indications. The Fatigue Severity Scale (FSS) (65), originally developed to assess fatigue in patients with multiple sclerosis or lupus erythemetatosus, can also be used for patients with chronic musculoskeletal pain.

\section{Sleep assessment}

Some of the most prominent complaints of patients with chronic pain concern sleep, excessive daytime sleepiness, and fatigue, rather than pain itself. Affected individuals frequently report light, easily-disturbed sleep, and daytime tiredness, fatigue or sleepiness. The accurate assessment of the changes in sleep associated with treatment is, therefore, critically important. Sleep quality can be assessed using the singleitem Sleep Quality NRS (66) that instructs patients to select the number that best describes the quality of your sleep during

Table III - Unidimensional fatigue tools.

\begin{tabular}{|l|l|}
\hline Measurements & Score \\
\hline 4-point verbal rating scales & None, mild, moderate, severe \\
\hline 5-point verbal rating scales & None, mild, moderate, severe, very severe \\
\hline 11-point NRS & $\begin{array}{l}\text { How severe has average fatigue been during the past week on a scale of } 0 \\
\text { (no fatigue) to10 (worst fatigue imaginable) scale }\end{array}$ \\
\hline & $\begin{array}{l}0=\text { None } \\
1=\text { Increased over baseline, but not altering normal activities }\end{array}$ \\
& $2=$ Moderate or causing difficulty performing some activities \\
4-point numeric scales & $4=$ Severe or loss of ability to perform some activities \\
& 0 (no fatigue) - 10 (worst possible fatigue) \\
\hline VAS &
\end{tabular}

NRS, Numeric Rating Scales; VAS, Visual Analogue Scale. 
the past 24 hours $(0=$ best possible sleep and $10=$ worst possible sleep), or multidimensional instruments. A variety of multidimensional measurement tools have proved to be useful for measuring sleep in rheumatic diseases, including the Medical Outcome Study (MOS) Sleep Scale (SS), the Pittsburgh Sleep Quality Index (PSQI), the Pittsburgh Sleep Diary (PSD) and the Insomnia Severity Index (ISI) $(67,68)$. The MOS Sleep Scale may be the best choice.

\section{Psychological assessment}

A number of studies have shown that chronic pain is associated with depression or other symptoms of psychological distress, as well as with a constellation of other health symptoms $(69,70)$. Psychological evaluation of patients with musculoskeletal pain can provide useful information concerning the psychological and behavioral characteristics that may influence their pain and dysfunction, and give a sense of the impact of pain, fatigue and other symptoms on their psychological health. Anxiety and depression can have a major impact on patients' quality of life $(69,70)$, and the associated symptoms (an inability to concentrate, loss of motivation, disturbed sleep, fatigue, pessimistic mood) may affect their ability to benefit from treatment and rehabilitation programs. Psychological evaluation instruments come in varying lengths and formats (71). Length is an important factor distinguishing the various scales and is defined on the basis of the number of questions or test items. Longer tests are more expensive to administer. These are sometimes needed to reach acceptable levels of reliability and validity, whereas screening instruments are short (sometimes ultra-short) measurements that are typically limited to one psychological domain such as depression or anxiety and are the easiest to implement in routine care settings. The brevity of ultra-short measurement tools offers a potential economic advantage because fewer staff resources are required for their completion. Short measurement tools (containing 5-20 items) include the Zung Self-rating De- pression Scale (ZSDS) (72), the Centre for Epidemiologic Studies-Depression Scale (73), the Hospital Anxiety and Depression Scale (74), and the Hamilton rating scales for anxiety (HARS) (75) or depression (76), all of which have been proved to have adequate psychometric properties. The long measurement tools (containing 21-50 items) include the Beck Depression Inventory (77), which meets all of the evaluation criteria, the Four-Dimensional Symptom Questionnaire (4DSQ) (78), the Symptom Checklist (SCL-90) (79), and the Rotterdam Symptom Checklist (80).

\section{Health-related quality of life assessment}

The importance of assessing HRQL in patients with chronic pain has been documented by our recent studies of patients with inflammatory rheumatic diseases (RA, psoriatic arthritis and ankylosing spondylitis) (70), systemic lupus erythematosus $(81,82)$, symptomatic knee and hip osteoarthritis (69), postmenopausal women with vertebral fractures (83), and fibromyalgia (59). In comparison with healthy controls, all of the rheumatic conditions significantly impaired all eight health concepts of the SF-36 in both the physical and mental component, but the disease with the worst HRQL for these dimensions was RA (70). Overall, the dimensions typically affected in inflammatory rheumatic diseases were physical functioning, limitations due to physical function, and bodily pain, whereas the level of perceived HRQL in patients with fibromyalgia seems to be explained more by their mental health than by their physical condition $(59,69,70,81-83)$. A number of pain-related quality of life selfadministered instruments have been constructed to evaluate pain-related functional disturbances in specific diseases or pain conditions in which the patient is asked to list the activities or tasks they regularly performed before the onset of pain but have since found difficult. When choosing the instruments to measure physical function and health status, a common distinction is drawn between generic and specific measurement tools $(84,85)$ : the 
first provide a broad picture of health status across a range of conditions, whereas the latter are more sensitive to the disorder under consideration and are, therefore, more likely to reflect clinically important changes.

\section{Generic measurement tools}

Generic measurement tools (typically developed for descriptive epidemiological or social science research purposes) may provide a profile of scores for different components of health status and HRQL, or operational definitions of various constructs summarized by a single index value. One concern with generic instruments is that they are sensitive to any changes in health (84-86) and so, if the primary interest is of a specific nature, other changes in general health interfere and may obscure the outcome of interest. Furthermore, a number of questions in a generic measurement tool may be inappropriate or irrelevant to a particular problem, or there may be too few items tapping a specific area (in an attempt to ensure a reasonable length). The most popular generic measurement tools are the SF-36 (60), the Sickness Impact Profile (SIP) (87), the Nottingham Health Profile (NHP) (88), and the European Quality of Life Measure (EQ-5D) (89).

\section{Disease specific measures}

Disease specific measurement tools are designed to assess specific diagnostic groups or patient populations, often with the aim of measuring responsiveness to treatment or clinically important changes $(84,85)$. One obvious disadvantage of some disease specific measurement tools is that they do not allow comparative judgements between the outcomes of different treatments in patients with different health problems (e.g. for resource allocation studies) for which it is suggested to combine their use with generic measurement procedures. However, there are some broad disease specific measurement tools such as the Fibromyalgia Impact Questionnaire (FIQ) $(90,91)$ or Revised Fibromyalgia Impact Questionnaire (FIQR) (92), the Arthritis Impact
Measurement Scales 2 (AIMS2) (93, 94), and the Health Assessment Questionnaire (HAQ) (95) which include general aspects of functional status together with specific references to states or changes of particular concern to the target population. These disease specific measurements, therefore, considerably overlap generic measurement procedures.

\section{CONCLUSIONS}

In conclusion, adequate assessment of chronic pain, using validated tools is an essential prerequisite of successful pain management. Over the past decade, a number of procedures and measurement tools have been developed to address assessment of chronic musculoskeletal pain and function in adults.

One problem is that it is difficult to select the most appropriate approach, i.e. one that is sufficiently comprehensive but efficient. Outcome measurement procedures should meet each of the three major criteria of validity, reliability and responsiveness: the first two are important for all measurement tools, but responsiveness (sensitivity to change) is the quintessential requirement for any procedure used to evaluate changes following effective treatment. Furthermore, some pragmatic issues are also important: interpretability (the measurement tools should give results that are easily understood by others), acceptability (how acceptable is the measurement procedure for respondents to complete in terms of response rates, time required, cultural applicability, and so on), and feasibility (ease of administration and processing: i.e. the effort and burden of staff, and disruption to clinical care, as well as the professional expertise required to apply or interpret the measurement procedure, and the presence of a clear instruction manual).

In conclusion, a wide selection of measurement tools are currently in use, some of which are new and others which are traditional and well-established concepts, all with their advantages and limitations. 


\section{REFERENCES}

1. Woolf AD, Pfleger B. Burden of major musculoskeletal conditions. Bull World Health Organization. 2003; 81: 646-56.

2. Centers for Disease Control and Prevention. Health-related quality of life among adults with arthritis-Behavioral Risk Factor Surveillance System, 11 states, 1996-1998. Morb Mortality Wkly Rep. 2000; 49: 366-9.

3. Reginster JY. The prevalence and burden of arthritis. Rheumatology. 2002; 41 (Suppl. 1): 3-6.

4. Chaiamnuay P, Darmawan J, Miurden KD, Assawatanabodee P. Epidemiology of rheumatic disease in rural Thailand: a WHO-ILAR COPCORD study. J Rheumatol. 1998; 25: 1382-7.

5. Chou CT, Pei L, Chang DM, et al. Prevalence of rheumatic diseases in Taiwan: a population study of urban, suburban, rural differences. J Rheumatol. 1994; 21: 302-6.

6. Picavet HSJ, Hazes JMW. Prevalence of self reported musculoskeletal diseases is high. Ann Rheum Dis. 2003; 62: 644-50.

7. Andrianakos A, Trontzas P, Christoyannis $F$, et al. Prevalence of rheumatic diseases in Greece: a cross-sectional population based epidemiological study. The ESORDIG study. J Rheumatol. 2003; 30: 1589-601.

8. Carmona L, Ballina J, Gabriel R, et al. The burden of musculoskeletal diseases in the general population of Spain: results from a national survey. Ann Rheum Dis. 2001; 60: 1040-5.

9. McCorrmic A, Fleming D, Charlton J. Royal College of General Pratictioner Morbidity Statistics from General Practice Fourth National Morbidity Survey 1991-1992. OPCS. London: HMSO.

10. Hagen KB, Björndal A, Uhlig T, Kvien TK. A population study of factors associated with general pratictioner consultation for noninflammatory musculoskeletal pain. Ann Rheum Dis. 2000; 59: 788-93.

11. Martin J, Meltzer H, Elliott D. The prevalence of disability among adults. OPCS Surveys of Great Britain. Report I. OPCS Social Surveys Division. London: HMSO, 1988; 1.

12. Urwin M, Symmons D, Allison T, et al. Estimating the burden of musculoskeletal disorders in the community: the comparative prevalence of symptoms at different anatomical sites, and the relation to social deprivation. Ann Rheum Dis. 1998; 57: 649-55.

13. Yelin E. The economics of osteoarthritis. In Brandt KD, Doherty M, Lohmander LS, eds. Osteoarthritis. New York, Oxford University Press. 1998; 23-30.

14. Coyte PC, Asche CV, Croxford R, Chan B. The economic cost of musculoskeletal disorders in Canada. Arthritis Care Res. 1998; 11: $315-25$.
15. March LM, Bachmeier CMJ. Economics of osteoarthritis: a global perspective. Baillieres' Clin Rheumatol. 1997; 11: 817-34.

16. Salaffi F, De Angelis R, Grassi W, et al. Prevalence of musculoskeletal conditions in an Italian population sample: results of a regional community-based study. I. The MAPPING study. Clin Exp Rheumatol. 2005; 23: 819-28.

17. Sokka T, Krishnan E. National databases and rheumatology research II: the National Health and Nutrition Examination Surveys. Rheum Dis Clin North Am. 2004; 30: 869-78.

18. Gran JT. The epidemiology of chronic generalized musculoskeletal pain. Best Pract Res Clin Rheumatol. 2003; 17: 547-61.

19. Cimmino MA, Parisi M, Moggiana GL, et al. Prevalence of self-reported peripheral joint pain and swelling in an Italian population: the Chiavari study. Clin Exp Rheumatol. 2001; 19: 35-40.

20. Dworkin RH, Turk DC, Farrar JT, et al. Core outcome measures for chronic pain clinical trials: IMMPACT recommendations. Pain. 2005; 113: 9-19.

21. Dworkin RH, Turk DC, Wyrwich KW, et al. Interpreting the clinical importance of treatment outcomes in chronic pain clinical trials: IMMPACT recommendations. J Pain. 2008; 9: 105-21.

22. Acquadro C, Berzon R, Dubois D, et al. Incorporating the patient's perspective into drug development and communication: an ad hoc task force report of the Patient-Reported Outcomes (PRO) Harmonization group Meeting at the Food and Drug Administration, February 16, 2001. Value Health. 2003; 6: 522-31.

23. Turk DC, Dworkin RH, Burke LB, et al. Developing outcome measures for pain clinical trials: IMMPACT recommendations. Pain. 2006; 125: 208-15.

24. Moher D, Schulz K, Altman DG, for the CONSORT Group. The CONSORT statement: revised recommendations for improving the quality of reports of parallel-group randomized trials. Ann Int Med. 2001; 134: 657-62.

25. Bellamy N, Kirwan J, Boers M, et al. Recommendations for a core set of outcome measures for future phase III clinical trials in knee, hip, and hand osteoarthritis: consensus development at OMERACT III. J Rheumatol. 1997; 24: 799-80.

26. Brooks P, Hochberg M; ILAR; OMERACT. Outcome measures and classification criteria for the rheumatic diseases. A compilation of data from OMERACT (Outcome Measures for Arthritis Clinical Trials), ILAR (International League of Associations for Rheumatology), regional leagues and other groups. Rheumatology (Oxford). 2001; 40: 896-906.

27. Salaffi F, Migliore A, Scarpellini M, et al. Psychometric properties of an index of three patient reported outcome (PRO) measures, 
termed the CLinical ARthritis Activity (PROCLARA) in patients with rheumatoid arthritis. The NEW INDICES study. Clin Exp Rheumatol. 2010; 28: 186-200.

28. Sokka T. Assessment of pain in patients with rheumatic diseases. In: Breivik H, Shipley M, ed. Pain Best Practice and Research Compendium. London: Elsevier. 2007; 27-42.

29. Jensen MP, Karoly P. Self-report scales and procedures for assessing pain in adults, Handbook of Pain Assessment, 2nd edition. Edited by Turk DC, Melzack R. New York, Guilford Press. 2001; 15-34.

30. Melzack R, Katz J. Pain assessment in adult patients. In: McMahon SB, Koltzenburg M, eds. Wall and Melzack's Textbook of Pain, 5th ed. London: Elsevier. 2006; 291-304.

31. Turk DC, Melzack R. In: Turk DC, Melzack R, editors. Handbook of pain assessment. 2nd ed. New York: Guilford Press. 2001.

32. Scott J, Huskisson EC. Graphic representation of pain. Pain. 1976; 2: 175-84.

33. Dixon JS. Agreement between horizontal and vertical visual analogue scales. Br J Rheumatol. 1986; 25: 415-6.

34. Jensen MP, Karoly P, Braver S. The measurement of clinical pain intensity: a comparison of six methods. Pain. 1986; 27: 117-26.

35. Taylor LJ, Harris J, Epps CD, Herr K. Psychometric evaluation of selected pain intensity scales for use with cognitively impaired and cognitively intact older adults. Rehabil Nurs. 2005; 30: 55-61.

36. Herr KA, Mobily PR. Comparison of selected pain assessment tools for use with the elderly. Appl Nurs Res. 1993; 6: 39-46.

37. Ferraz MB, Quaresma MR, Aquino LRL, Atra E, Tugwell P, Goldmith CH. Reliability of pain scales in the assessment of literate and illiterate patients with rheumatoid arthritis. J Rheumatol. 1990; 17: 1022-4.

38. Price DD, Bush FM, Long S, Harkins SW. A comparison of pain measurement characteristics of mechanical visual analogue and simple numerical rating scales. Pain. 1994; 56: 217-26.

39. Ritter PL, González VM, Laurent DD, Lorig KR. Measurement of pain using the visual numeric scale. J Rheumatol. 2006; 33: 574-80.

40. Pincus T, Bergman M, Sokka T, et al. Visual analog scales in formats other than a 10 centimeter horizontal line to assess pain and other clinical data. J Rheumatol. 2008; 35: 1550-8.

41. Paice JA, Cohen FL. Validity of a verbally administered numeric rating scale to measure cancer pain intensity. Cancer Nurs. 1997; 20: 88-93.

42. Salaffi F, Stancati A, Silvestri CA, et al. Minimal clinically important changes in chronic musculoskeletal pain intensity measured on a numerical rating scale. Eur J Pain. 2004; 8: 283-91.

43. Herr K, Spratt KF, Garand L, Li L. Evalua- tion of the Iowa pain thermometer and other selected pain intensity scales in younger and older adult cohorts using controlled clinical pain: a preliminary study. Pain Med. 2007; 8: 585-600.

44. Grossi E, Borghi C, Cerchiari EL, et al. Analogue chromatic continuous scale (ACCS): a new method for pain assessment. Clin Exp Rheumatol. 1983; 1: 337-40.

45. Gracely RH, Kwilosz DM. The descriptor differential scale: applying psychophysical principles to clinical pain assessment. Pain. 1988; 35: 279-88.

46. Ware LJ, Epps CD, Herr K, Packard A. Evaluation of the revised faces pain scale, verbal descriptor scale, numeric rating scale, and Iowa pain thermometer in older minority adults. Pain Manag Nurs. 2006; 7: 117-25.

47. McGrath PJ, Walco G, Turk DC, et al. Core outcome domains and measures for pediatric acute and chronic/recurrent pain clinical trials: PedIMMPACT recommendations. J Pain. 2008; 9: 771-83.

48. Hadjistavropoulos T, Herr K, Turk DC, et al. An interdisciplinary expert consensus statement on assessment of pain in older persons. Clin J Pain. 2007; 23 (Suppl. 1): S1-43.

49. Wolfe F, Clauw DJ, Fitzcharles MA, et al. The American College of Rheumatology preliminary diagnostic criteria for fibromyalgia and measurement of symptom severity. Arthritis Care Res (Hoboken). 2010; 62: 600-10.

50. Wolfe F. Pain extent and diagnosis: development and validation of the regional pain scale in 12,799 patients with rheumatic disease. J Rheumatol. 2003; 30: 369-78.

51. Salaffi F, Sarzi-Puttini P, Girolimetti R, et al. Development and validation of the selfadministered Fibromyalgia Assessment Status: a disease-specific composite measure for evaluating treatment effect. Arthritis Res Ther. 2009; 11: R125.

52. Turk DC, Rudy TE. Toward an empirically derived taxonomy of chronic pain patients: integration of psychological assessment data. J Consult Clin Psychol. 1988; 56: 23-8.

53. Melzack R. The McGill Pain Questionnaire: major properties and scoring methods. Pain. 1975; 1: 277-99.

54. Melzack R. The Short-Form McGill Pain Questionnaire. Pain. 1987; 30: 191-7.

55. Cleeland CS, Ryan KM. Pain assessment: global use of the Brief Pain Inventory. Ann Acad Med Singapore. 1994; 23: 129-38.

56. Vonkorff M, Ormel J, Keefe FJ, Dworkin SF. Grading the severity of chronic pain. Pain. 1992; 50: 133-49.

57. Salaffi F, Stancati A, Grassi W. Reliability and validity of the Italian version of the Chronic Pain Grade questionnaire in patients with musculoskeletal disorders. Clin Rheumatol. 2006; 25: 619-31. 
58. Nolli M, Salaffi F, Ferraccioli GF, et al. Analysis of variables of Melzack's semantic questionnaire in patients with osteoarthrosis. Minerva Anestesiol. 1988; 54: 215-22.

59. Salaffi F, Sarzi-Puttini P, Girolimetti R, et al. Health-related quality of life in fibromyalgia patients: a comparison with rheumatoid arthritis patients and the general population using the SF-36 health survey. Clin Exp Rheumatol. 2009; 27 (5 Suppl. 56): S67-74.

60. Ware JE JR, Sherbourne CD. The MOS 36item short form health survey (SF-36). 1. Conceptual frame-work and item selection. Med Care. 1992; 30: 473-81.

61. Ware JE, Kosinski M, Keller SD. SF-36 physical and mental health summary scales: a user's manual. Boston: The Health Institute, New England Medical Centre. 1994.

62. Tack BB. Fatigue in rheumatoid arthritis: conditions, strategies, and consequences. Arthritis Care Res. 1990; 3: 65-70.

63. Smets EM, Garssen B, Bonke B, De Haes JC. The Multidimensional Fatigue Inventory (MFI) psychometric qualities of an instrument to assess fatigue. J Psychosom Res. 1995; 39: 315-25.

64. Yellen SB, Cella DF, Webster K, et al. Measuring fatigue and other anemia-related symptoms with the Functional Assessment of Cancer Therapy (FACT) measurement system. J Pain Symptom Management. 1997; 13: 63-74.

65. Krupp LB, Larocca NG, Muir-Nash J, Steinberg AD. The fatigue severity scale: application to patients with multiple sclerosis and systemic lupus erythematosus. Arch Neurol. 1989; 46: 1121-3.

66. Martin S, Chandran A, Zografos L, Zzateva G. Evaluation of the impact of fibromyalgia on patients' sleep and the content validity of two sleep scales. Health Qual Life Outcomes. 2009; 7: 64.

67. Hays R, Stewart A. Sleep measures. In Measuring functioning and well-being: the medical outcomes study approach edited by: Stewart A, Ware J. Durham. Duke University Press. 1992; 235-59.

68. Buysse DJ, Reynolds CF, Monk TH, et al. The Pittsburg sleep quality index: a new instrument for psychiatric practise and research. Psychiatry Res. 1989; 28: 193-213.

69. Salaffi F, Carotti M, Stancati A, Grassi W. Health-related quality of life in older adults with symptomatic hip and knee osteoarthritis: a comparison with matched healthy controls. Aging Clin Exp Res. 2005; 17: 255-63.

70. Salaffi F, Carotti M, Gasparini S, Intorcia M, Grassi W. The health-related quality of life in rheumatoid arthritis, ankylosing spondylitis, and psoriatic arthritis: a comparison with a selected sample of healthy people. Health Qual Life Outcomes. 2009; 7: 25.

71. Salaffi F, Sarzi-Puttini P, Ciapetti A, Atzeni
F. Assessment instruments for patients with fibromyalgia: properties, applications and interpretation. Clin Exp Rheumatol. 2009; 27 (5 Suppl. 56): S92-105.

72. Zung WWK. From art to science. Arch Gen Psychiatry. 1973; 29: 328-37.

73. Radloff L. The CES-D scale: a self-report depression scale for research in the general population. Appl Psychol Meas. 1977; 1: 385-401.

74. Zigmond AS, Snaith RP. The Hospital Anxiety and Depression Scale. Acta Psychiatr Scand. 1983; 67: 361-70.

75. Hamilton M. The assessment of anxiety states by rating. Br J Med Psychol. 1959; 32: 50-5.

76. Hamilton M. Rating depressive patients. J Clin Psychiatry. 1980; 41: 2124.

77. Beck AT, Ward CH, Mendelson M, Mock J, Erbaugh J. An inventory for measuring depression. Arch Gen Psychiatry. 1961; 4: 561-71.

78. Terluin B, van Marwijk HWJ, Ader HJ, et al. The Four-Dimensional Symptom Questionnaire (4DSQ): a validation study of a multidimensional self-report questionnaire to assess distress, depression, anxiety and somatization. BMC Psychiatry. 2006; 6: 34.

79. Derogatis L. SCL-90-R administration, scoring and practice manual Baltimore, MD. Clinical Psychiatric Research. 2000.

80. De Haes JC, van Knippenberg FC, Neijt JP. Measuring psychological and physical distress in cancer patients: structure and application of the Rotterdam symptom checklist. Br J Cancer. 1990; 62: 1034-8.

81. Doria A, Rinaldi S, Ermani M, et al. Healthrelated quality of life in Italian patients with systemic lupus erythematosus. II. Role of clinical, immunological and psychological determinants. Rheumatology (Oxford). 2004; 43: 1580-6.

82. Rinaldi S, Doria A, Salaffi F, et al. Healthrelated quality of life in Italian patients with systemic lupus erythematosus. I. Relationship between physical and mental dimension and impact of age. Rheumatology (Oxford). 2004; 43: 1574-9.

83. Salaffi F, Cimmino MA, Malavolta N, et al. Italian Multicentre Osteoporotic Fracture Study Group. The burden of prevalent fractures on health-related quality of life in postmenopausal women with osteoporosis: the IMOF study. J Rheumatol. 2007; 34: 1551-60.

84. Salaffi F, Ciapetti A, Gasparini S, Carotti M. Questionari di valutazione della disabilità e della qualità della vita. In: Patient-reported outcomes in reumatologia. Scale e questionari. Ed. Mattioli (1885) 2012; 73-140.

85. Franchignoni F, Salaffi F. Generic and specific measures for outcome assessment in orthopaedic and rheumatologic rehabilitation. In: Assessment in physical medicine and rehabilitation - advances in rehabilitation. Barat M, Franchignoni F, eds. 2004; 16: 45-77. 
86. Salaffi F, Stancati A, Carotti M. Responsiveness of health status measures and utilitybased methods in patients with rheumatoid arthritis. Clin Rheumatol. 2002; 21: 478-87.

87. Bergner N, Bobbitt RA, Carter WB, Gilson BS. The sickness impact profile: development and final revision of a health status measure. Med Care. 1981; 19: 787-805.

88. Hunt SM, McKenna SP, McEwen J. The Nottingham health profile: subjective health status and medical consultations. Soc Sci Med. 1981; 15: 221-9.

89. Brooks R. EuroQol: the current state of play. Health Policy. 1996; 37: 53-72.

90. Burkhart CS, Clark SR, Bennett RM. The fibromyalgia impact questionnaire: development and validation. J Rheumatol. 1991; 18: 728-33.

91. Sarzi Puttini P, Atzeni F, Fiorini T, et al. Validation of an Italian version of the Fibromyal- gia Impact Questionnaire (FIQ-I). Clin Exp Rheumatol. 2003; 21: 459-64.

92. Bennett RM, Friend R, Jones KD, et al. The Revised Fibromyalgia Impact Questionnaire (FIQR): validation and psychometric properties. Arthritis Res Ther. 2009; 11: 415.

93. Meenan RF, Mason JH, Anderson JJ, et al. AIMS2. The content and properties of a revised and expanded arthritis impact measurement scales health status questionnaire. Arthritis Rheum. 1992; 35: 1-10.

94. Salaffi F, Piva S, Barreca C, et al. Validation of an Italian version of the arthritis impact measurement scales 2 (ITALIAN-AIMS2) for patients with osteoarthritis of the knee. Gonarthrosis and Quality of Life Assessment (GOQOLA) Study Group. Rheumatology. 2000; 39: 720-7.

95. Fries JF, Spitz PW, Kraines RG, Holman HR. Measurement of patient outcome in arthritis. Arthritis Rheum. 1980; 23: 137-45. 